\title{
On the Effect of the Stress Ratio on Fatigue Properties of Ti-6Al- 4V Produced by Laser Powder Bed Fusion
}

\author{
A. Cutolo $\mathbb{D}^{1,2}$ C. Elangeswaran $\mathbb{D}^{1,},{ }^{1,2}$ and B. Van Hooreweder $\mathbb{D}^{1}$ \\ ${ }^{1}$ KU Leuven, Department of Mechanical Engineering, Celestijnenlaan 300, 3001 Leuven, Belgium \\ ${ }^{2}$ SIM M3 Program, Technologiepark 48, 9052 Zwijnaarde, Belgium
}

Correspondence should be addressed to B. Van Hooreweder; brecht.vanhooreweder@kuleuven.be

Received 10 November 2021; Revised 19 January 2022; Accepted 27 January 2022; Published 14 February 2022

Academic Editor: Guian Qian

Copyright (c) 2022 A. Cutolo et al. This is an open access article distributed under the Creative Commons Attribution License, which permits unrestricted use, distribution, and reproduction in any medium, provided the original work is properly cited.

\begin{abstract}
Fatigue life estimation of Ti-6Al-4V parts produced by additive manufacturing (AM) technologies has received increasing interest during the last decade. Recent studies focused mostly on the fatigue performance of Ti-6Al-4V considering a fixed stress ratio $(R)$, usually 0.1 or -1 . However, in order to properly design structural components subjected to variable loads, the effect of different stress ratios on the fatigue performance has to be carefully investigated. This research studies the stress ratio influence on the fatigue properties of Ti-6Al-4V specimens produced by laser powder bed fusion (L-PBF). Miniaturized Ti-6Al-4V samples were tested with the step procedure for different $R$ values. A constant life Haigh's diagram $\left(2 \cdot 10^{6}\right.$ cycles $)$ was generated for LPBF Ti-6Al-4V in as-built, electro-polished, and machined surface condition. The results present for the first time the relations between alternating and mean stresses for L-PBF Ti-6Al-4V with a fine $\alpha+\beta$ microstructure when different surface posttreatments are used to enhance the coupons' final surface quality.
\end{abstract}

\section{Introduction}

Among the additive manufacturing (AM) processes, the laser powder bed fusion (L-PBF) technique is currently one of the most widely used manufacturing technology for functional part production [1], no longer restricted to mainly prototyping. By combining the L-PBF technique with novel design algorithms, this process enables the production of complex geometries with substantial material saving if compared with conventional manufacturing techniques.

Given its high strength to weight ratio and its excellent weldability properties, Ti-6Al-4V is of particular interest for L-PBF production of lightweight components.

However, to meet the more and more stringent requirements of part integrity in the aerospace, automotive, and biomedical industries, detailed mechanical behaviour investigations of $\mathrm{L}-\mathrm{PBF} \mathrm{Ti}-6 \mathrm{Al}-4 \mathrm{~V}$ components are required. In this respect, there has been a growing interest in the fatigue characterisation of this alloy created using AM methods in recent years [2-6]. Despite the efforts of several researchers all over the world, the state of the art lacks a proper characterisation of the L-PBF Ti-6Al-4V fatigue dependency from the mean stress. Moreover, the literature on conventionally manufactured Ti-6Al-4V fatigue performance reports a variety of mean stress relations [7-11] highlighting the need to extend this research to L-PBF Ti-6Al-4V.

As far as the authors know, there are only two studies that report the fatigue sensitivity to the mean stress of this alloy processed by L-PBF. Wycisk et al. [12] investigated hot isostatic-pressed (HIP) coupons as well as stressrelieved (SR) ones in machined surface condition. The results were presented in terms of Smith's diagram, namely, maximum stress expressed in function of the mean stress. Wycisk et al. reported a quasilinear relation between maximum and mean stress for SR coupons whereas a parabolic one has been reported for HIP samples. On the other hand, Benedetti et al. [13] investigated the mean stress sensitivity for Ti-6Al-4V specimens in as-produced surface condition and with a very fine $\alpha+\beta$ microstructure. Three different stress ratios were considered, and exponential mean stress sensitivity was observed. 
In the present study, the data reported by Wycisk et al. and Benedetti et al. are extended with a thorough experimental campaign on $\mathrm{L}-\mathrm{PBF} \mathrm{Ti}-6 \mathrm{Al}-4 \mathrm{~V}$ specimens with a fine $\alpha+\beta$ Widmanstätten microstructure fatigued with different $R$ values. Three different surface conditions were investigated, namely, as-produced, electro-plasma-polished, and machined conditions, for which three different mean stress sensitivities have been evaluated: for machined and electroplasma-polished coupons, two linear relations are reported, whereas for as-produced samples an exponential relation has been found to be the best fit. The constant life Haigh's diagram proposed in the present study allows the definition of fatigue guidelines that can be used for functional part design that have to withstand variable alternating loads.

\section{Materials and Methods}

2.1. Production and Posttreatments. The specimen geometry considered for this research is shown in Figure 1. The geometry presents a continuous radius between the two gripping cylinders, with the smallest cross-sectional diameter of $2.5 \mathrm{~mm}$. This geometry has been specifically designed to assess the fatigue properties of additively manufactured metals [14-16].

The test coupons were produced by L-PBF using a ProX320 machine (3D Systems) using LaserForm ${ }^{\circledR}$ Ti Gr23 powder (3D Systems). A layer thickness of $60 \mu \mathrm{m}$ and optimized commercially available production parameters were used for the manufacturing [17]. The specimens were manufactured with the symmetry axis $z$ (Figure 1 ) oriented perpendicularly to the build platform of the L-PBF system.

In order to reduce the inherent residual stresses generated during the L-PBF production, all the coupons were subjected to a standard stress-relieving operation, as defined by Vrancken et al. [18]. This treatment consists of heating the coupons to $850^{\circ} \mathrm{C}$ for 2 hours. The resulting microstructure was analysed on ground, polished, and etched sample using a Philips XL 30 FEG scanning electron microscope (SEM). The static properties were evaluated on machined coupons according to the ASTM E8 standard.

The surface quality of the as-produced (ASB) coupons has been enhanced performing two surface posttreatments, namely, an electro-plasma polishing (EPP) and a machining treatment (MC). EPP was performed by Plasmatec B.V. by submerging the samples in a plasma cloud, using their default parameters for titanium. On the other hand, the MC samples were obtained from turning hexagonal bars to the geometry of Figure 1, aiming at a surface roughness smaller than $0.2 \mu \mathrm{m} R_{a}$.

\subsection{Fatigue Experiments and Haigh's Diagram Definition.} Fatigue experiments were performed on an Instron E10000 machine equipped with $10 \mathrm{kN}$ load cell. The tests were force controlled and a $30 \mathrm{~Hz}$ sinusoidal load was applied to the specimens with different $R$ ratio defined as the minimum stress to maximum stress ratio. Post-mortem fractured surfaces were analysed using a Philips XL 30 FEG SEM system.

In order to evaluate the coupons' fatigue strength at 2 . $10^{6}$ cycles, the step procedure, developed by Maxwell and

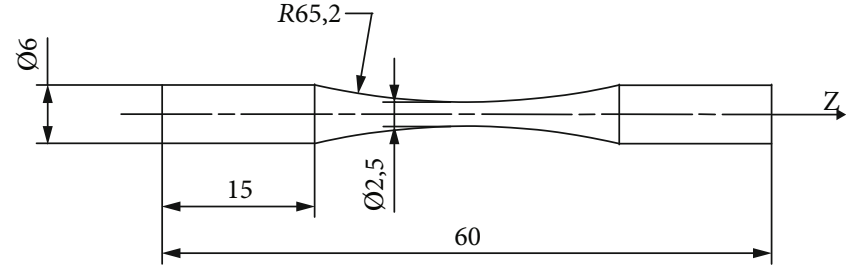

Figure 1: Specimen geometry utilized for this investigation.

Nicholas [19], has been adopted. For a given stress ratio $R$, a specimen was fatigued at a stress level lower than the expected fatigue limit. If the specimen does not fail before $2 \cdot 10^{6}$ cycles, then the stress amplitude is increased of $\Delta \sigma$ $=5.5 \% \sigma_{y}$, with $\sigma_{y}$ being the yield strength of the material. The fatigue strength at $2 \cdot 10^{6}$ cycles is calculated according to the following equation:

$$
\sigma_{W}=\sigma_{a_{N-1}}+\Delta \sigma\left(\frac{N_{f}}{2 \cdot 10^{6}}\right)
$$

in which $\sigma_{a_{N-1}}$ is the stress amplitude of the last step that survived $2 \cdot 10^{6}$ cycles and $N_{f}$ is the number of cycles to failure.

For each combination of surface condition and $R$ ratio, 3 coupons were tested except for the combination "Machined - $R=-0.3$ ” for which one single specimen was fatigued.

Each experimental test result has been plotted on a $\sigma_{a}$ $-\sigma_{m}$ diagram, also known as Haigh's diagram, to evaluate the relation between the stress amplitude and the mean stress (or the stress ratio $R$ ) for all the investigated surface conditions.

\section{Results and Discussion}

3.1. Results of Volumetric and Surface post-treatments. Figure 2(a) shows a SEM image of the L-PBF Ti-6Al-4V microstructure obtained after the stress-relieving operation. The picture shows a fine $\alpha+\beta$ Widmanstätten microstructure. This particular microstructure guarantees a good compromise between strength and ductility with a yield strength $\sigma_{y}$ equal to $914 \mathrm{MPa}$ and strain at maximum stress equal to $10.15 \%$. Detailed material characterisation of this microstructure is described in the work of Vrancken et al. [18]. Typically, in a dual-phase lamellar matrix, slip bands within the $\alpha$ lamellae or $\alpha$ zones along prior $\beta$ grain boundaries act as favourable crack initiation sites [20]. In lamellar microstructures, the colony size determines the slip length, which in turn influences the onset of plastic deformation. However, in a basket weave or Widmanstätten microstructure, since such well-defined colonies do not exist, a single lamellar width is indicative of the slip characteristics and strength [21]. Resistance to dislocation motion and fatigue crack initiation is therefore dependent on slip characteristics within the $\alpha$ lamellae [22].

The benefit of the surface treatments was analysed by measuring the coupons' surface roughness. The two postprocesses enhanced the surface quality of as-produced coupons by completely eliminating partly molten particles 


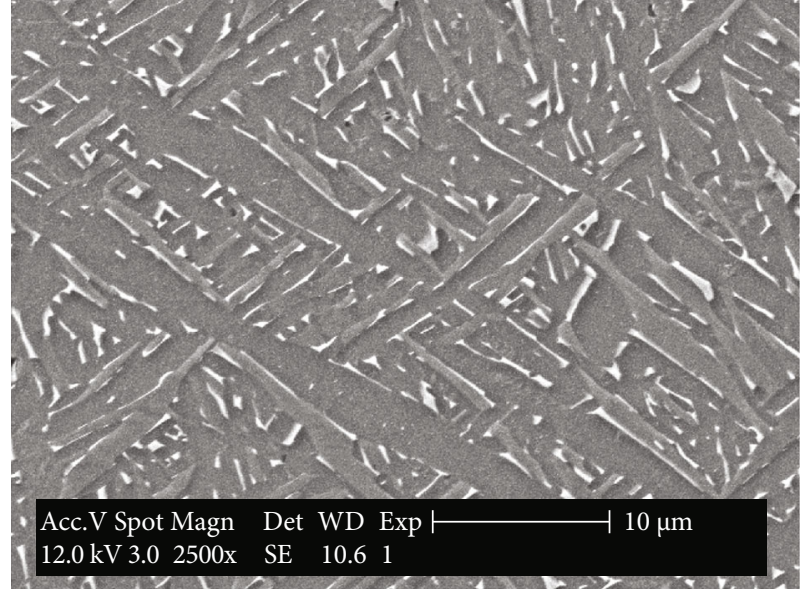

(a)

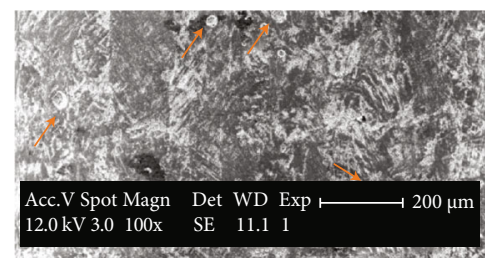

(c)

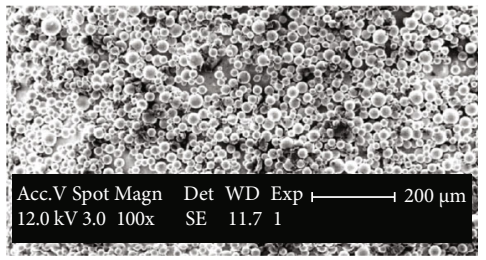

(b)

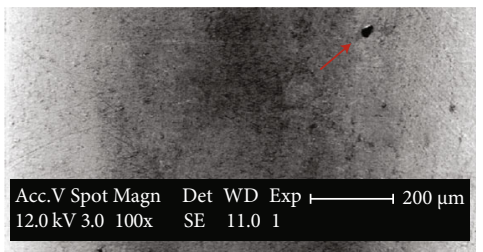

(d)

Figure 2: (a) Ti-6Al-4V microstructure resulting from stress-relieving operation. Representative external surface of the (b) as-produced, (c) electro-polished, and (d) machined specimens. Orange and red arrows indicate surface defects.

and by smoothening the wavy surface typical of layer-bylayer production processes. The lowest values for surface roughness parameters were reported for MC coupons with $R_{a}$ and $R_{v}$, respectively, equal to $0.11 \mu \mathrm{m}$ and $0.40 \mu \mathrm{m}$. EPP specimens exhibit $R_{a}$ and $R_{v}$ equal to $2.77 \mu \mathrm{m}$ and $9.31 \mu \mathrm{m}$ whereas $R_{a}=9.11 \mu \mathrm{m}$ and $R_{v}=24.54 \mu \mathrm{m}$ were measured for ASB samples. From the SEM images of Figure 2 that represent the external surfaces of coupons in different conditions, it is possible to qualitatively appreciate how the as-produced surface (Figure $2(\mathrm{a})$ ) has been modified by the EPP (Figure 2(b)) and MC (Figure 2(c)) treatments. Despite the fact that the post-treatments significantly enhanced surface quality, it is crucial to note that the EPP generated undesirable surface defects comparable to semispherical voids, as represented by the orange arrows in Figure 2(c). Furthermore, subsurface pores were opened by the machining operation as presented by the red arrow in Figure 2(d).

3.2. Fatigue Haigh's Diagram. The results of the experimental fatigue campaign are reported in the Haigh's diagram of Figure 3(a). The Haigh's diagram shows the dependency of the fatigue performance from the stress ratio $R$. As expected, L-PBF Ti-6Al-4V coupons exhibit poorer fatigue performance when higher mean stresses are applied as the presence of a positive mean stress facilitates crack initiation. However, three different responses to the mean stress can be appreciated in function of the material surface condition.
The low surface roughness of MC coupons guaranteed very high fatigue performance, with fatigue strength (expressed in terms of stress amplitudes) of $531 \mathrm{MPa}, 404$ $\mathrm{MPa}, 310 \mathrm{MPa}$, and $187 \mathrm{MPa}$ for $R$ equal to $-1,-0.3,0.1$, and 0.5 , respectively. L-PBF Ti-6Al-4V that underwent MC surface treatment outperformed the other two surface conditions investigated in this study, i.e., EPP and ASB. The relation between stress amplitude and mean stress follows a linear trend with the Soderberg's equation being the best fitting curve to describe this relation:

$$
\sigma_{a_{R \neq-1}}=\sigma_{a_{R=-1}}\left(1-\frac{\sigma_{m}}{\sigma_{y}}\right),
$$

with $\sigma_{a_{R f-1}}$ being the stress amplitude in the presence of a mean stress, $\sigma_{a_{R=-1}}$ is the stress amplitude with 0 applied mean stress, and $\sigma_{m}$ is the mean stress.

Similar trend, but with lower values of the mean stresses and amplitudes, is exhibited by L-PBF Ti-6Al-4V coupons treated with electro-plasma-polishing operations. Stress amplitudes for $R=-1$ and 0.1 were found to be equal to $330 \mathrm{MPa}$ and $210 \mathrm{MPa}$, respectively. For this condition, the Soderberg's equation (2) can also be used as mean stress correction law considering $\sigma_{a_{R=-1}}=330 \mathrm{MPa}$.

L-PBF Ti-6Al-4V coupons in as-produced surface condition exhibit a different trend. ASB coupons show stress amplitude of $233 \mathrm{MPa}, 129 \mathrm{MPa}$, and $105 \mathrm{MPa}$ for $R$ equal to $-1,0.1$, and 0.5 , respectively. In this case, an exponential relation, 


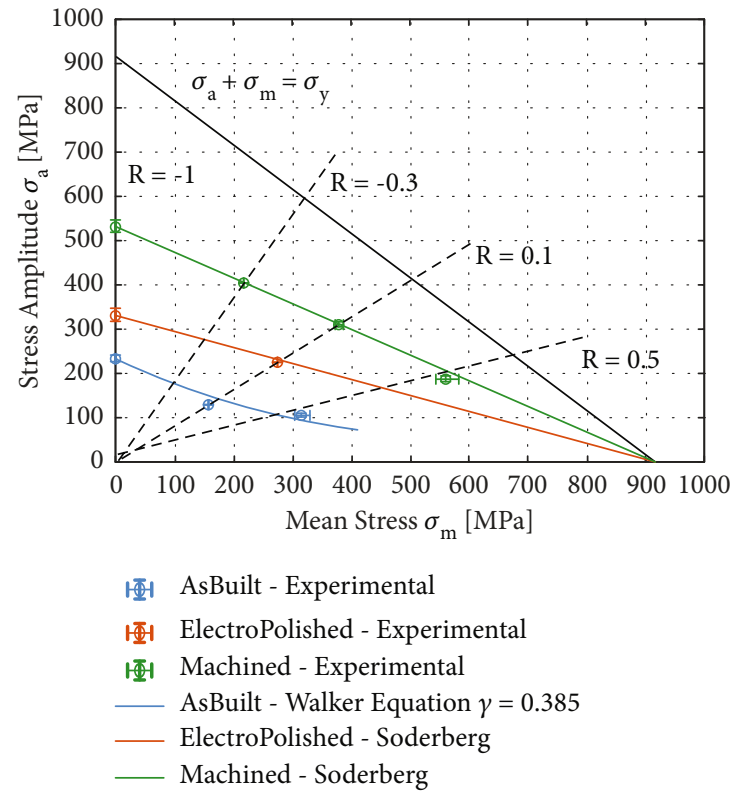

(a)

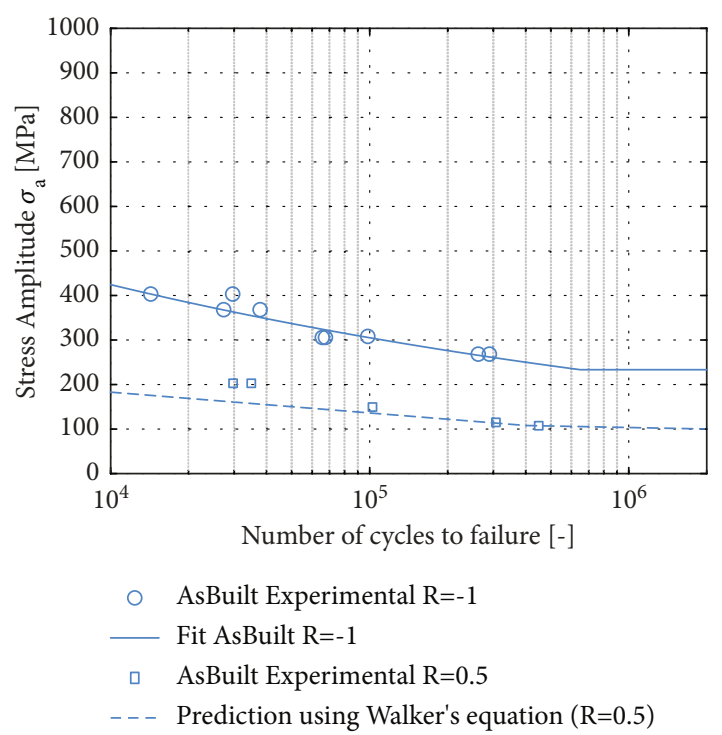

(b)

FIGURE 3: (a) Haigh's diagram for L-PBF Ti-6Al-4V coupons subjected to different surface treatments. (b) Experimental fatigue data for asproduced coupons tested with $R=-1$ and $R=0.5$. Data for $R=-1$ gathered from [16].

namely, the Walker's equation (3), has been found to be the best fitting curve to relate mean and stress amplitude:

$$
\sigma_{a_{R \neq-1}}=\sigma_{a_{R=-1}}\left(\frac{1-R}{2}\right)^{\gamma},
$$

with $\gamma$ being the Walker's coefficient equal to 0.385 .

In the case of ASB coupons, the Walker's coefficient lower than 0.5 indicates a higher sensitivity to the positive mean stress if compared to a linear relation.

To appreciate the prediction capabilities of Walker's equation (equation (3)) for the as-produced surface condition, five additional coupons have been tested under a stress ratio $R=0.5$ with a stress amplitude higher than $105 \mathrm{MPa}$ until the final failure of the samples. The results are presented in Figure 3(b) in terms of stress amplitude and number of cycles to failure. The data have been compared with the fatigue resistance of stress-relieved ASB Ti-6Al-4V coupons subjected to a stress ratio of $R=-1$ presented in a previous study by Cutolo et al. [16]. The SN curve for $R=-1$ presented in Figure 3(b) has been scaled to a stress ratio of $R=0.5$ adopting equation (3) to predict the fatigue behaviour of the 5 additional coupons. The predicted SN curve for $R=0.5$ captures the fatigue resistance of the tested specimens very well, especially for the life range $10^{5}-10^{6}$ cycles, indicating that Walker's equation can be adopted as a predictive tool to evaluate the fatigue properties of L-PBF Ti6Al-4V with as-produced surface condition.

In a recent study performed by Benedetti et al. [13], the authors reported the sensitivity of the fatigue life to mean stress of Ti-6Al-4V coupons produced by L-PBF in as-produced surface condition. Those coupons showed slightly lower mean stress sensitivity, and a SmithWatson-Topper (SWT) relation was used to describe the stress amplitude in function of the mean stress. The SWT equation is a particular case of the Walker's relation in which the $\gamma$ coefficient is equal to 0.5 . The lower sensitivity reported by Benedetti et al. could be explained by the combined effect of a lower surface roughness of the samples and a finer $\alpha+\beta$ microstructure. In fact, several studies on the mean stress influence on $\mathrm{Ti}-6 \mathrm{Al}-4 \mathrm{~V}$ produced with conventional manufacturing techniques [7, $10,23,24]$ indicate the microstructure morphology as the main factor that changed the material fatigue response when subjected to positive mean stresses.

A similar transition from a linear relation (for $\mathrm{MC}$ and EPP coupons) to an exponential relation (for ASB samples) shown in the Haigh's diagram of Figure 3(a) has been reported by Lanning et al. [8] for Ti-6Al-4V coupons produced via conventional manufacturing technique. In Lanning et al.'s study, a quasi-exponential relation between $\sigma_{a}$ and $\sigma_{m}$ was used to fit experimental fatigue data obtained on coupons designed with severe geometrical discontinuities with stress concentration factors greater than 4 , indicating that also the sample geometry influences the material ability to react to positive mean stresses.

The Walker's coefficient found for ASB coupons should be considered not as intrinsic material property [25] but rather a defect-sensitivity parameter. In this case, low $\gamma$ could be associated with the high surface defect density of ASB samples that leads to premature failures in the presence of high stress ratio $R$ if compared with EPP and MC coupons. The link between the Walker's parameter and defect population has been reported in literature $[26,27]$ for aluminium alloys suggesting that the mean stress effect in 

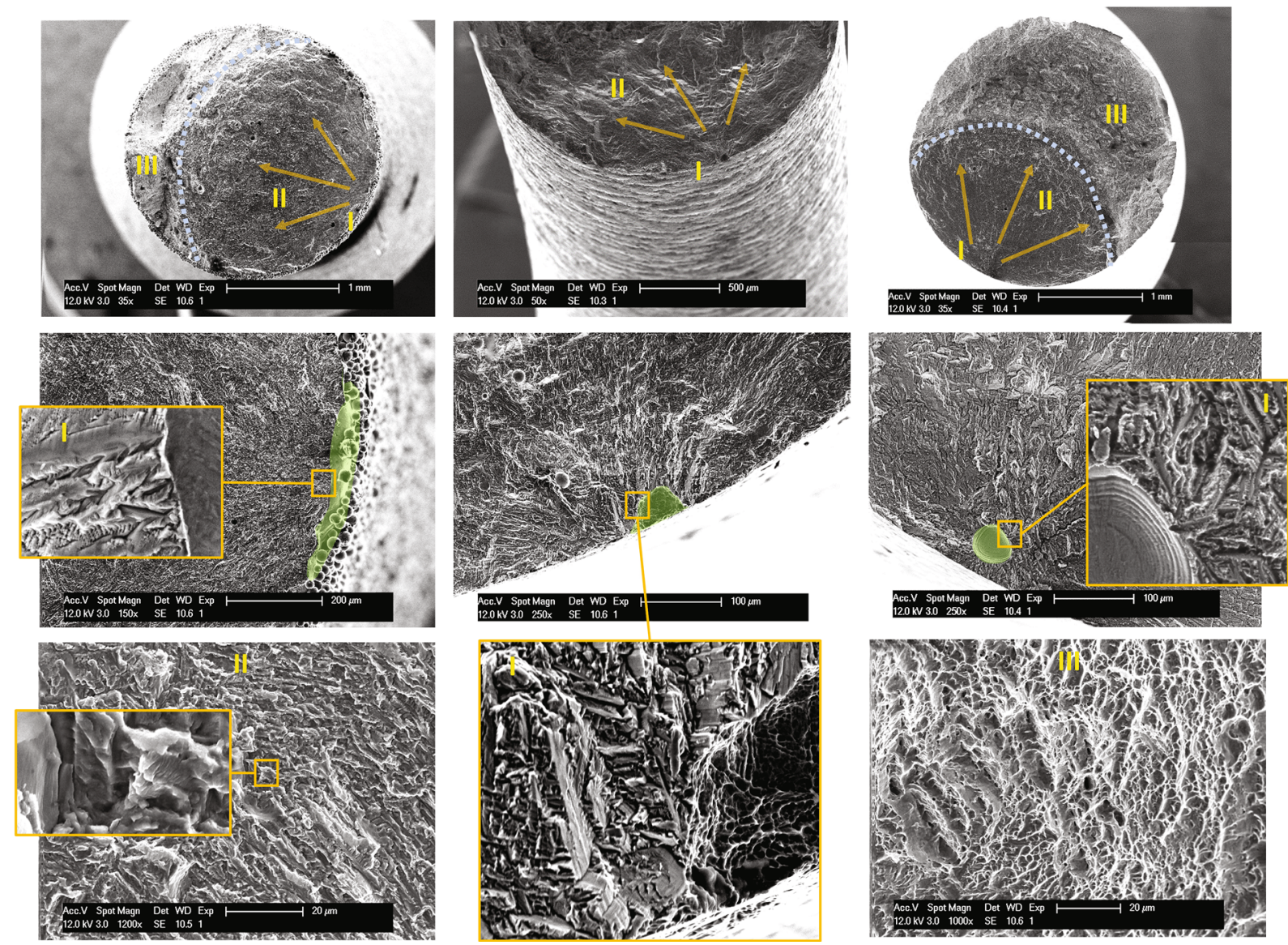

FIGURE 4: Representative fractured surfaces of (a) as-produced, (b) electro-plasma-polished, and (c) machined coupons. Representative crack initiation site for (d) as-produced, (e) electro-plasma-polished, and (f) machined coupons. Representative failure mechanism phase (g) II and (h) III.

proximity of a structural defect is mainly influenced by the defect type and the level of the mean stress rather than only by material-related aspects.

3.3. Fractured Surfaces. Fractography was performed on the tested specimens to assess whether there were any changes in fatigue failure mechanisms between the specimens that were treated with different surface posttreatments. From this analysis, two main conclusions could be extracted.

On the one hand, the failure mechanism followed three different phases: initiation (I in Figure 4(a)) propagation (II in Figure 4(a)), and final fracture (III in Figure 4(a)). For the three conditions studied, this failure resulted in a similar mechanism. In phase I, the crack initiation zone possesses a tortuous fracture surface that is the result of a combination of intergranular and transgranular crack path along the $\alpha$ and $\beta$ grains. In the second phase (II), crack propagation occurs. The tortuous feature disappeared and the typical striations were observed (Figure $4(\mathrm{~g})$ ). The final fracture of the coupons occurred in phase III. Equiaxed dimples were observed in this zone as presented in Figure 4(h).

On the other hand, the crack initiation location is different for the three conditions investigated as presented by Figures $4(\mathrm{~d})-4(\mathrm{f})$. For as-produced coupons, the crack initi- ated at the external surface in correspondence of relatively large surface defects. Figures 4(a) and 4(d) show a representative initiation location for ASB samples. It can be observed that the surface defect can be considered as a lack of material in between two successive layers that are generated by the layer-by-layer production L-PBF technique. The crack initiated at the root of these defects that act as micronotches and, therefore, as local stress raisers that facilitated the damage initiation. These surface defects can be treated as microcracks. In this view, these microcracks could easily evolve into large cracks, especially in the presence of a positive mean stress, explaining the higher sensitivity of asproduced to the higher stress ratios if compared to the EPP and MC samples.

Regarding the crack initiation location of EPP coupons, the SEM investigation on the fractured surfaces suggested that the failures initiated at surface defects that resemble semispherical shape. These defects have been generated during the EPP treatment. The treatment randomly generated these crater-like defects that act as stress raiser on the surface. Figures 4(b) and 4(e) present a representative defect generated during the EPP process that was responsible for the crack initiation of the investigated coupon. It is remarkable to highlight that the coupons' external surface in 
correspondence of these defects presents elongated dimples (detail presented in Figure 4(e)), possibly generated by the removal of agglomerates of partially molten particles during the EPP process.

For the machined coupons, the initiation started at subsurface locations, in correspondence of almost spherical pores that were generated during the manufacturing process. Figure 4(f) shows one of these pores that caused the failure of the specimen under investigation.

\section{Conclusions}

The main findings of the present study can be summarized as follows:

(i) Ti-6Al-4V specimens produced by L-PBF are very sensitive to the stress ratio $R$, with fatigue strength becoming lower and lower with increasing $R$ (or positive mean stress);

(ii) Given the same stress ratio $R$, machined coupons exhibited the higher fatigue resistance, followed by electro-plasma-polished and as-produced samples;

(iii) The relation between the mean and stress amplitude can be described by the Soderberg's equation for both machined and electro-plasma-polished coupons, whereas an exponential Walker's equation has to be adopted for as-produced parts;

(iv) The Walker's relation has been adopted to predict the fatigue behaviour of as-built L-PBF Ti-6Al-4V coupons in the life range $10^{4}-10^{6}$ cycles for a stress ratio $R=0.5$. The comparison of the prediction with experimental data shows the efficacy of the proposed model to capture the fatigue resistance of as-built L-PBF Ti-6Al-4V coupons.

It has to be mentioned here that the results presented in this study are valid for the fine $\alpha+\beta$ Widmanstätten microstructure generated by the stress-relieving operation. Any other microstructure obtained via different volumetric posttreatments might lead to different stress ratio sensitivity of the L-PBF Ti-6Al-4V coupons.

\section{Data Availability}

Data are available on request.

\section{Conflicts of Interest}

The authors declare that they have no conflicts of interest.

\section{Acknowledgments}

The authors gratefully acknowledge the financial support of SIM (Strategic Initiative Materials in Flanders) and VLAIO (Flemish government agency, Flanders Innovation \& Entrepreneurship) for their support of the ICON project "M3FATAM" (HBC.2016.0446), which is part of the research program MacroModelMat (M3), coordinated by Siemens
(Siemens Digital Industries Software, Belgium). Moreover, the authors thankfully acknowledge 3D Systems Leuven for the high quality of the parts that were provided to conduct this investigation.

\section{References}

[1] B. Blakey-Milner, P. Gradl, G. Snedden et al., "Metal additive manufacturing in aerospace: a review," Materials \& Design, vol. 209, article 110008, 2021.

[2] B. Van Hooreweder, D. Moens, R. Boonen, J.-P. Kruth, and P. Sas, "Analysis of fracture toughness and crack propagation of Ti6Al4V produced by selective laser melting," Advanced Engineering Materials, vol. 14, no. 1-2, pp. 92-97, 2012.

[3] E. Wycisk, A. Solbach, S. Siddique, D. Herzog, F. Walther, and C. Emmelmann, "Effects of defects in laser additive manufactured Ti-6Al-4V on fatigue properties," Physics Procedia, vol. 56, pp. 371-378, 2014.

[4] W. Jonathan, "Fatigue life estimation of additive manufactured parts in the as-built surface condition," Material Design \& Processing Communications, vol. 1, no. 3, article e36, 2019.

[5] A. Fatemi, R. Molaei, J. Simsiriwong et al., "Fatigue behaviour of additive manufactured materials: an overview of some recent experimental studies on Ti-6Al-4V considering various processing and loading direction effects," Fatigue \& Fracture of Engineering Materials \& Structures, vol. 42, no. 5, pp. 9911009, 2019.

[6] P. Edwards and M. Ramulu, "Fatigue performance evaluation of selective laser melted Ti-6Al-4V," Materials Science and Engineering: A, vol. 598, pp. 327-337, 2014.

[7] B. Oberwinkler, "On the anomalous mean stress sensitivity of Ti-6Al-4V and its consideration in high cycle fatigue lifetime analysis," International Journal of Fatigue, vol. 92, pp. 368381, 2016.

[8] D. B. Lanning, T. Nicholas, and G. K. Haritos, "On the use of critical distance theories for the prediction of the high cycle fatigue limit stress in notched Ti?6Al? $4 \mathrm{~V}^{*} 1$," International Journal of Fatigue, vol. 27, no. 1, pp. 45-57, 2005.

[9] R. K. Nalla, R. O. Ritchie, B. L. Boyce, J. P. Campbell, and J. O. Peters, "Influence of microstructure on highcycle fatigue of Ti6Al-4V: bimodal vs. lamellar structures," Metallurgical and Materials Transactions A, vol. 33, no. 3, pp. 899-918, 2002.

[10] Y. Ono, T. Yuri, T. Ogata, S. Matsuoka, and H. Sunakawa, "Effect of stress ratio on high-cycle fatigue properties of Ti6Al-4V ELI alloy forging at low temperature," in AIP Conference Proceedings, pp. 23-26, American Institute of Physics, Japan, 2014.

[11] Y. Furuya and E. Takeuchi, "Gigacycle fatigue properties of Ti6Al-4V alloy under tensile mean stress," Materials Science and Engineering: A, vol. 598, pp. 135-140, 2014.

[12] E. Wycisk, S. Siddique, D. Herzog, F. Walther, and C. Emmelmann, "Fatigue performance of laser additive manufactured Ti-6Al-4V in very high cycle fatigue regime up to 109 cycles," Frontiers in Materials, vol. 2, p. 72, 2015.

[13] M. Benedetti, V. Fontanari, M. Bandini, F. Zanini, and S. Carmignato, "Low- and high-cycle fatigue resistance of Ti$6 \mathrm{Al}-4 \mathrm{~V}$ ELI additively manufactured via selective laser melting: mean stress and defect sensitivity," International Journal of Fatigue, vol. 107, pp. 96-109, 2018.

[14] C. Elangeswaran, A. Cutolo, G. K. Muralidharan et al., "Effect of post-treatments on the fatigue behaviour of 316L stainless 
steel manufactured by laser powder bed fusion," International Journal of Fatigue, vol. 123, pp. 31-39, 2019.

[15] C. Elangeswaran, K. Gurung, R. Koch, A. Cutolo, and B. Van Hooreweder, "Post-treatment selection for tailored fatigue performance of $18 \mathrm{Ni} 300$ maraging steel manufactured by laser powder bed fusion," Fatigue \& Fracture of Engineering Materials \& Structures, vol. 43, no. 10, pp. 2359-2375, 2020.

[16] A. Cutolo, C. Elangeswaran, C. de Formanoir, G. K. Muralidharan, and B. Van Hooreweder, "Effect of heat treatments on fatigue properties of $\mathrm{Ti}-6 \mathrm{Al}-4 \mathrm{~V}$ and $316 \mathrm{~L}$ produced by laser powder bed fusion in as-built surface condition," in TMS 2019 148th Annual Meeting \& Exhibition Supplemental Proceedings, pp. 395-405, New York, 2019.

[17] A. Beckers, G. K. Muralidharan, K. Lietaert et al., "On the advances to obtain excellent and repeatable mechanical properties and build quality of LaserForm ${ }^{\circledR} \mathrm{Ti}$ gr23 (A) across whole build platform," in MATEC Web of Conferences, p. 14, Leuven, Belgium, 2020.

[18] B. Vrancken, L. Thijs, J.-P. Kruth, and J. Van Humbeeck, "Heat treatment of Ti6Al4V produced by selective laser melting: microstructure and mechanical properties," Journal of Alloys and Compounds, vol. 541, pp. 177-185, 2012.

[19] D. C. Maxwell and T. Nicholas, A rapid method for generation of a Haigh diagram for high cycle fatigue, ASTM International, West Conshohocken, Pennsylvania, 29th edition, 1999.

[20] T. S. Balasubramanian, V. Balasubramanian, M. A. Muthu, and Manickam, "Fatigue crack growth behaviour of gas tungsten arc, electron beam and laser beam welded Ti-6Al-4V alloy," Materials \& Design, vol. 32, no. 8-9, pp. 4509-4520, 2011.

[21] M. Simonelli, Y. Y. Tse, and C. Tuck, "Effect of the build orientation on the mechanical properties and fracture modes of slm Ti-6Al-4V," Materials Science and Engineering: A, vol. 616, pp. 1-11, 2014.

[22] G. E. R. D. Lütjering, "Influence of processing on microstructure and mechanical properties of $\left(\_\alpha+\beta \_\right)$titanium alloys," Materials Science and Engineering: $A$, vol. 243, no. 1-2, pp. 32-45, 1998.

[23] G. Lütjering and J. C. Williams, Titanium Matrix Composites, Springer, Berlin, Heidelberg, 2007.

[24] K. S. Chan, "Roles of microstructure in fatigue crack initiation," International Journal of Fatigue, vol. 32, no. 9, pp. 1428-1447, 2010.

[25] N. E. Dowling, C. A. Calhoun, and A. Arcari, "Mean stress effects in stress-life fatigue and the Walker equation," Fatigue \& Fracture of Engineering Materials \& Structures, vol. 32, no. 3, pp. 163-179, 2009.

[26] M. I. Houria, Y. Nadot, R. Fathallah, M. Roy, and D. M. Maijer, "Influence of casting defect and SDAS on the multiaxial fatigue behaviour of A356-T6 alloy including mean stress effect," International Journal of Fatigue, vol. 80, pp. 90-102, 2015.

[27] K. Gall, M. F. Horstemeyer, B. W. Degner, D. L. McDowell, and J. Fan, "On the driving force for fatigue crack formation from inclusions and voids in a cast A356 aluminum alloy," International Journal of Fracture, vol. 108, no. 3, pp. 207233, 2001. 